\title{
Investigations on the microstructure and mechanical properties of multi-pass PCGTA welding of super-duplex stainless steel
}

\author{
K DEVENDRANATH RAMKUMAR*, DEBIDUTTA MISHRA, G THIRUVENGATAM, \\ S P SUDHARSAN, TADIKONDA HARSHA MOHAN, VIMAL SAXENA, RACHIT PANDEY \\ and N ARIVAZHAGAN \\ School of Mechanical \& Building Sciences, VIT University, Vellore 632 014, India
}

MS received 12 June 2014; accepted 1 January 2015

\begin{abstract}
This paper addresses the weldability, microstructure and mechanical properties of the multi-pass welding of super-duplex stainless steel (SDSS). Pulsed current gas tungsten arc welding (PCGTAW) was carried out employing ER2553 and ERNiCrMo-4 fillers. Microstructure examination showed the presence of austenite in different forms at the weld zone of ER2553 whereas multi-directional grain growth was observed for ERNiCrMo-4 welds. Tensile and impact studies corroborated that the weldments employing ER2553 exhibited better results compared with ERNiCrMo-4 weldments. Detailed structure-property relationships of the weldments have been reported in the present study. The results corroborated that the enhanced properties could be achieved with the matching filler wire compared with the over-alloyed filler.
\end{abstract}

Keywords. Pulsed current; super-duplex stainless steel; fillers; microstructure; mechanical property.

\section{Introduction}

Super-duplex stainless steel (SDSS), UNS S32750 has a wide range of applications in the marine, chemical geothermal, power generation sectors owing to the combined properties of toughness and strength because of the presence of dual phase structure of ferrite and austenite. The excellent corrosion resistance offered by the alloy extended its use both in high temperature $\left(300^{\circ} \mathrm{C}\right)$ and cryogenic $\left(-50^{\circ} \mathrm{C}\right)$ environments. Nitrogen is usually added as an alloying element to accelerate the formation of the austenite phase and stabilize it, and also to improve pitting corrosion resistance. Although duplex/SDSS exhibits good weldability, the melting and solidification associated with the fusion welding processes tend to destroy the favourable duplex microstructure of this stainless steel. ${ }^{1,2}$ In order to maintain the phase balance between austenite and ferrite, it is necessary to provide proper heat input during welding.

Although higher heat inputs and slow cooling rates produce a favourable phase balance, it may also result in the formation of coarse grains with the precipitation of brittle inter-metallic phases. ${ }^{3}$ Similarly faster cooling rates exhibited in electron beam welding (EBW) and laser beam welding (LBW) resulted in the formation of $\mathrm{Cr}_{2} \mathrm{~N}$ and other deleterious phases. Hence a moderate cooling rate would be necessary to achieve the control of unwanted, deleterious phases. It was reported that the cooling rate plays a key role on the phase balance in the HAZ and weld and also significantly

\footnotetext{
*Author for correspondence (deva@ vit.ac.in)
}

affects the formation of inter-metallic phases and corrosion resistance of SDSS weldments. ${ }^{3}$

Karunakaran ${ }^{4}$ reported that the rate of heat input during welding followed by the nature of cooling has a strong influence on the grain size and phase formation. It was recommended that super-duplex steels must be welded with heat inputs in the range of $0.5-2.0 \mathrm{~kJ} \mathrm{~mm}^{-1}$, depending on the thickness and joint geometry. ${ }^{2}$

Pulsed current gas tungsten arc welding (PCGTAW) is one of the widely employed welding techniques in contrast to continuous current gas tungsten arc welding (CCGTAW) due to the effective and controlled heat input which in turn exhibits moderating cooling rates. In PCGTA welding, the current is pulsating between high and low levels of short or long time interval so that it brings the weld zone to the melting point during the pulse current period and allows the molten weld pool to cool and solidify during the background current period.

Several researchers addressed that the PCGTA welding is found to be an effective method for welding similar/dissimilar alloys. The typical advantages accrued from the PCGTA welding include (i) lesser distortion, (ii) control over the current and heat input, (iii) balanced phase formation, (iv) reduced width of heat-affected zone (HAZ), (v) reduced porosity and segregation, etc.

As stated earlier, the heat input plays a major role in maintaining the phase balance. A higher amount of the ferrite content in the weld zone was reported to have lower toughness and lower contents of ferrite could result in the lowering of stress corrosion cracking (SCC) resistance. ${ }^{5}$ It was reported that austenite content lower than $25 \%$ are not 
usually accepted for most of the industrial applications. ${ }^{6}$ Norsok Standard ${ }^{7}$ for welding and piping inspection recommended having a minimum content of $30 \%$ austenite in the final bead and root pass as necessary values to accept the weld joints.

Shing-Hoa Wang et $a l^{8}$ reported that pulsed welding coupled with a faster cooling rate can induce the content of austenite to increase under conditions without the addition of alloy or post-weld heat treatment on the duplex stainlesssteel weldments. Yousefieh et $a l^{9}$ investigated the effect of heat input on the corrosion properties of SDSS. The authors concluded that a heat input of $0.95 \mathrm{~kJ} \mathrm{~mm}^{-1}$ offered best corrosion characteristics and a balanced ferrite-austenite proportion, and resulted in the absence of deleterious phases such as sigma and $\mathrm{Cr}_{2} \mathrm{~N}$.

Next to the welding process, the selection of filler metals plays a major role in influencing the metallurgical and mechanical properties of the weldments. Several studies showed that Ni-based filler metals showed better mechanical properties and thermal stability. It was reported that the presence of $\mathrm{Nb}$ in the filler wire improves the resistance to hot cracking tendency. ${ }^{10}$ The over-alloyed Ni-based filler metals could be chosen for welding SDSS as they could improve the high-temperature strength and pitting corrosion resistance. ${ }^{11}$

In the present study, an attempt has been made to investigate the effect of current pulsing on the weldability, microstructure and mechanical properties of SDSS using ER2553 and ERNiCrMo-4 fillers. These fillers are expected to generate either partial or complete amounts of austenite in the weld zone. Also a comparison was made to establish the role of ferritic-austenitic (ER2553) and completely austenitic fusion zone (ERNiCrMo-4) on the weld mechanical properties. The outcomes of the study will be highly beneficial to industries employing SDSS joints.

\section{Experimental}

\subsection{Base metal and welding technique}

The chemical composition of the base and filler metals was tested using dry spectroscopic method and is represented in table 1. Welding was carried out on the base metal SDSS plates which were machined to have the dimensions of
$150 \times 55 \times 6 \mathrm{~mm}$ using wire-cut electrical discharge machining (EDM). A special welding jig (rigid fixture) with a grooved copper back plate (to dissipate the heat quickly) was employed to hold the parts in alignment and to ensure for accurate grip without bending. Standard butt joint configuration (single V-groove having a root gap of $2 \mathrm{~mm}$, size land of $1 \mathrm{~mm}$ and included angle of $70^{\circ}$ ) was chosen for the current study and shown in figure 1a. The process parameters were established based on the trial runs and are represented in table 2. The photographs of the welded samples employing ER2553 and ERNiCrMo-4 filler metals are shown in figure 1b. Furthermore, the PCGTA weldments obtained from these filler wires were assessed for their metallurgical and mechanical properties to understand the structure-property relationships of these weldments.

\subsection{Metallurgical and mechanical characterization}

Gamma-ray radiography non-destructive testing (NDT) technique was employed to investigate the PCGTA weldments for any weld defects. Followed by the NDT results, the welded samples were sliced into coupons of various dimensions to perform various metallurgical and mechanical tests to assess the nature of the weldments.

Optical microscopy (OM), scanning electron microscopy (SEM) and energy-dispersive X-ray analysis (EDAX) techniques were employed to investigate the microstructure features of the weldments. Both the metallographic examination and hardness measurement were carried out on the coupon designated as 'composite zone' whose dimensions are 30 $\times 10 \times 6 \mathrm{~mm}$, covering all the zones (parent metal-heat affected zone (HAZ)-weld zone) of the weldments. Standard metallographic procedures including polishing with emery sheets of $\mathrm{SiC}$ with grit size varying from 220 to 1000 followed by disc polishing using alumina and distilled water were employed on these coupons to obtain a mirror finish of $1 \mu \mathrm{m}$ on the weldments. Electrolytic etching (10\% oxalic acid; 6 V DC supply; current density of $1 \mathrm{~A} \mathrm{~cm}^{-2}$ ) was used to examine the microstructures. The mechanical properties of the weldments were established by conducting tensile and impact studies. The transverse coupons covering all the zones of the weldments were sliced to ascertain the mechanical properties.

Table 1. Chemical composition of the base and filler metals.

\begin{tabular}{|c|c|c|c|c|c|c|c|c|c|}
\hline & $\mathrm{C}$ & $\mathrm{Si}$ & $\mathrm{Mn}$ & $\mathrm{Cr}$ & Mo & $\mathrm{Fe}$ & $\mathrm{Ni}$ & $\mathrm{N}$ & Others \\
\hline $\begin{array}{l}\text { Super-duplex } \\
\text { stainless steel } \\
\text { (UNS32750) }\end{array}$ & 0.029 & 0.395 & 0.789 & 24.86 & 3.63 & Bal & 6.42 & 0.262 & $\begin{array}{l}\mathrm{P}-0.029 \\
\mathrm{~S}-0.005\end{array}$ \\
\hline ER2553 & 0.025 & 0.28 & 0.82 & 25.2 & 3.3 & Bal & 5.5 & 0.25 & $\begin{array}{c}\mathrm{P}-0.02 \\
\mathrm{~S}-0.003\end{array}$ \\
\hline ERNiCrMo-4 & 0.02 & 0.05 & 0.85 & 15.5 & 15.2 & 6.5 & Bal & Nil & $\begin{array}{c}\mathrm{Cu}-0.35 \\
\mathrm{Co}-0.12 \\
\mathrm{~W}-3.1 \\
\mathrm{~V}-0.13\end{array}$ \\
\hline
\end{tabular}




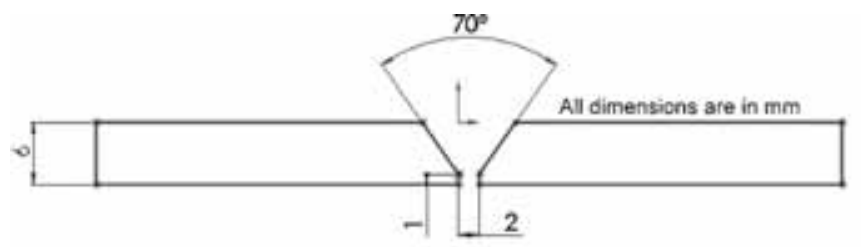

(a)
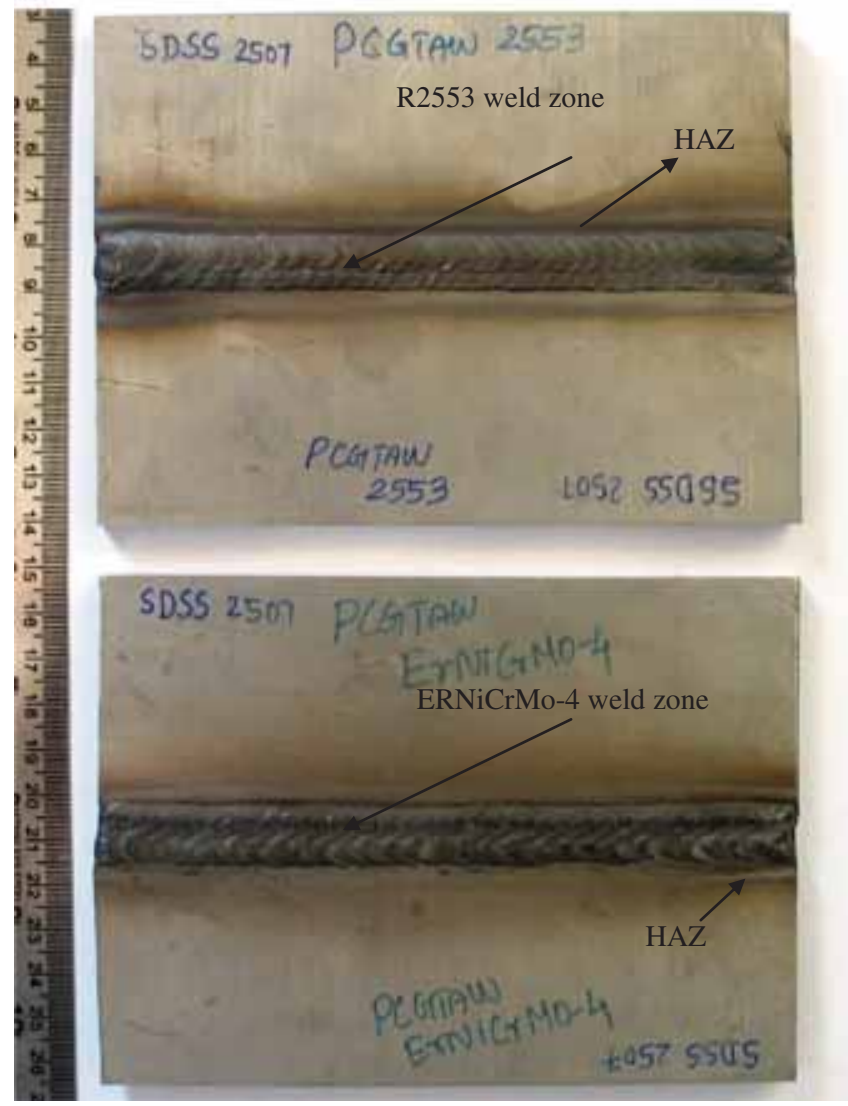

(b)
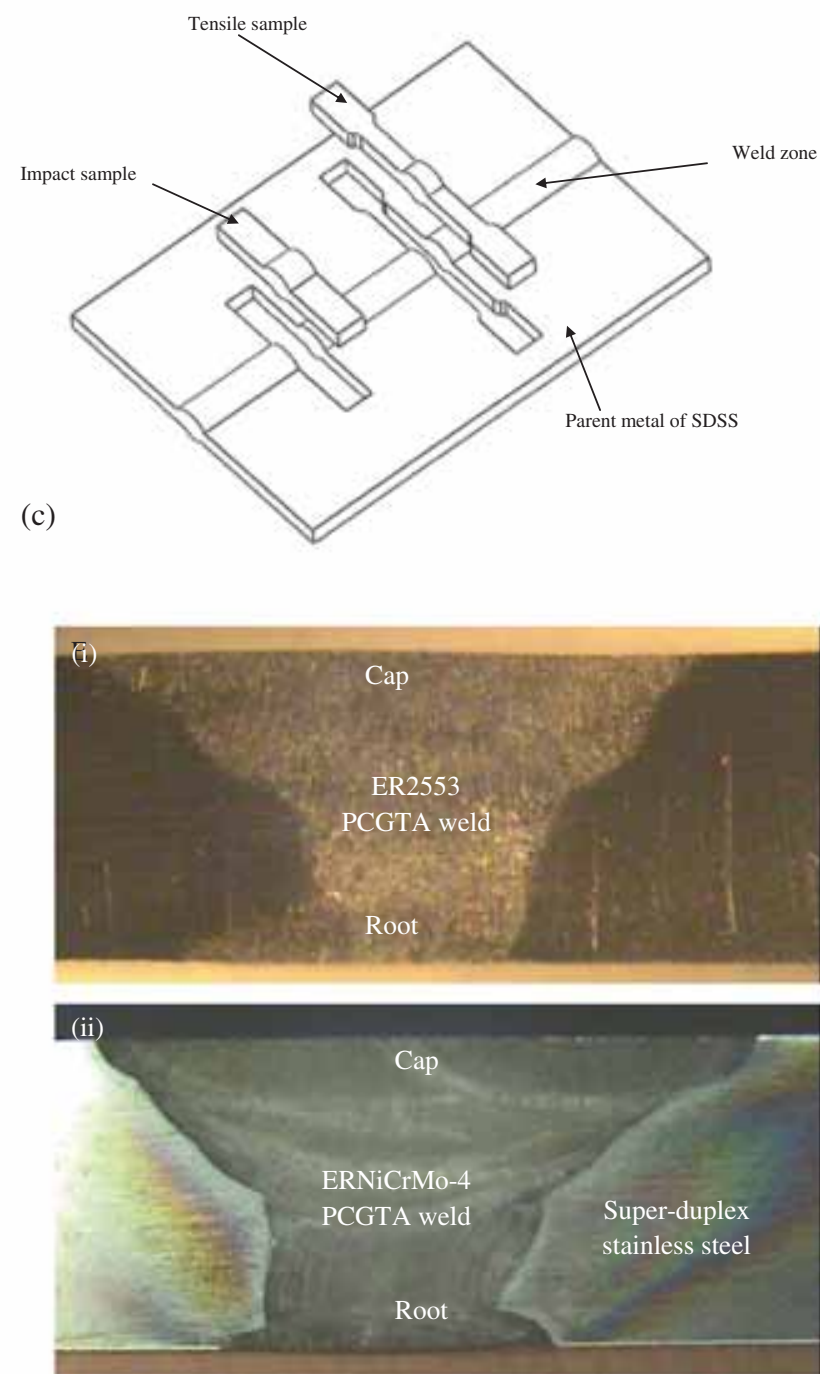

(d)

Figure 1. (a) Standard V-Butt configurations employed for PCGTA welding of super-duplex stainless steel, (b) PCGTA welding of super-duplex stainless steel employing ER2553 and ERNiCrMo-4 fillers, (c) CAD model representing the coupons obtained from the SDSS weldments for carrying out tensile and impact studies and (d) macrostructure of PCGTA weldments of super-duplex stainless steel employing (i) ER2553 and (ii) ERNiCrMo-4 fillers.

Micro-hardness studies were carried out on the transverse coupons of SDSS weldments. The measurements were carried out across the entire width of the weldments by keeping weld as centre using Vicker's micro-hardness tester. A standard load of $500 \mathrm{gf}$ was applied for a dwell period of $10 \mathrm{~s}$ and the measurements were carried out at regular intervals of $0.25 \mathrm{~mm}$. Tensile properties of the weldments were determined on the samples which were typically dimensioned as per ASTM: E8/E8M-13a standards. The cross head velocity was maintained at $2 \mathrm{~mm} \mathrm{~min}{ }^{-1}$ to establish uniform strain rate. Three trials of experiments were performed using the Instron Universal testing machine. Charpy V-notch impact test was conducted on the sub-sized coupons of the weldments prepared according to the ASTM: E23-12c standards. The samples were cleaned ultrasonically before the images were captured. The fractured samples were characterized using SEM analysis to understand the mode of fracture.

\section{Results}

\subsection{Macro- and microstructure examination}

Gamma-ray NDT inspection technique ascertained that both the weldments were free from surface/sub-surface defects. Macrostructure examination shown in figure 1d clearly witnessed narrow weld beads and also a proper fusion with the base metals on employing these fillers. Microstructure features at the HAZ of ER2553 weldment showed the dark regions of ferrite and white regions of austenite (figure 2a). Similarly skeletal, bony appearance of ferrite along with the 
white regions of austenite was witnessed at the HAZ-parent metal side of ERNiCrMo-4 filler. A slight grain coarsening was also observed at the HAZ of ERNiCrMo-4 (figure 2c).

Weld microstructure shown in figure $2 \mathrm{~b}$ depicted the presence of ferrite (as dark regions) and different forms of austenite such as grain boundary austenite, needleand wedge-shaped Widmanstätten austenite and inter/intragranular austenite while employing ER2553 filler; whereas multi-directional grain growth was observed at the weld zone employing ERNiCrMo-4 filler (figure 2c). Both cellular and dendritic growth could be visualized at this zone.

\subsection{SEM/EDAX analysis}

SEM analysis on the ER2553 weld zone clearly showed the presence of ferrite and various forms of austenite. Also the amount of $\mathrm{Cr}, \mathrm{Ni}, \mathrm{Fe}$ and $\mathrm{Mo}$ in the ferrite matrix and austenite phase was found to be similar as inferred from the point analysis (figure 3). Similarly the dendritic arm of the weld as well as the matrix of ERNiCrMo-4 weld zone consisted of $\mathrm{Ni}, \mathrm{Cr}, \mathrm{W}$ and $\mathrm{Mo}$ in almost equal proportions (figure 4).

\subsection{Mechanical characterization of weldments}

3.3a Hardness test: Hardness measurements were carried out on the cross-sectioned coupons across the different passes of the weldments shown in figure 5. It is envisaged that there were not much variations observed in the hardness profile of ER2553 weldments. The average hardness at the weld zone employing ER2553 in different passes was found to be $315 \mathrm{HV}$ and average peak hardness in the weldment

Table 2. Process parameters employed in PCGTA welding.

\begin{tabular}{lccccccc}
\hline \multirow{2}{*}{ Filler wire } & Pass & $\begin{array}{c}\text { Voltage } \\
(\mathrm{V})\end{array}$ & \multicolumn{2}{c}{ Current $(\mathrm{A})$} & Frequency & Filler wire dia. \\
ER2553 & Root & $11.5-12.0$ & 205 & 165 & 6 & 25 & 2.4 \\
& Filler & $14.1-15.2$ & 215 & 165 & 6 & & \\
& Cap & $15.5-16.1$ & 205 & 165 & 6 & & \\
ERNiCrMo-4 & Root & $11.5-12.0$ & 210 & 160 & 6 & 25 & 2.4 \\
& Filler & $13.5-14.2$ & 208 & 162 & 6 & & \\
& Cap & $15.0-15.4$ & 205 & 165 & 6 & & \\
\hline
\end{tabular}
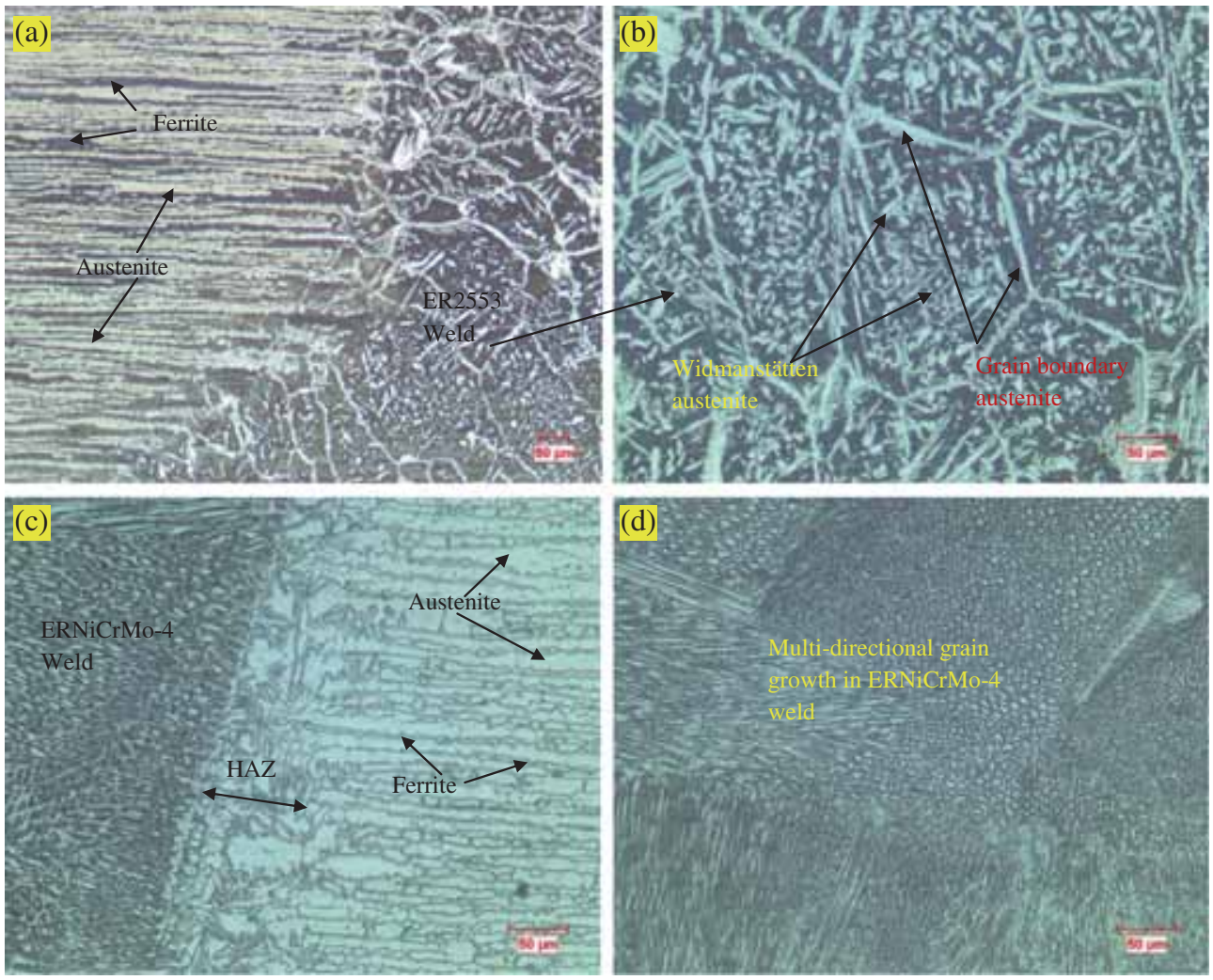

Figure 2. Interface and weld microstructures of PCGTA weldments employing (a and b) ER2553 and (c and d) ERNiCrMo-4. 


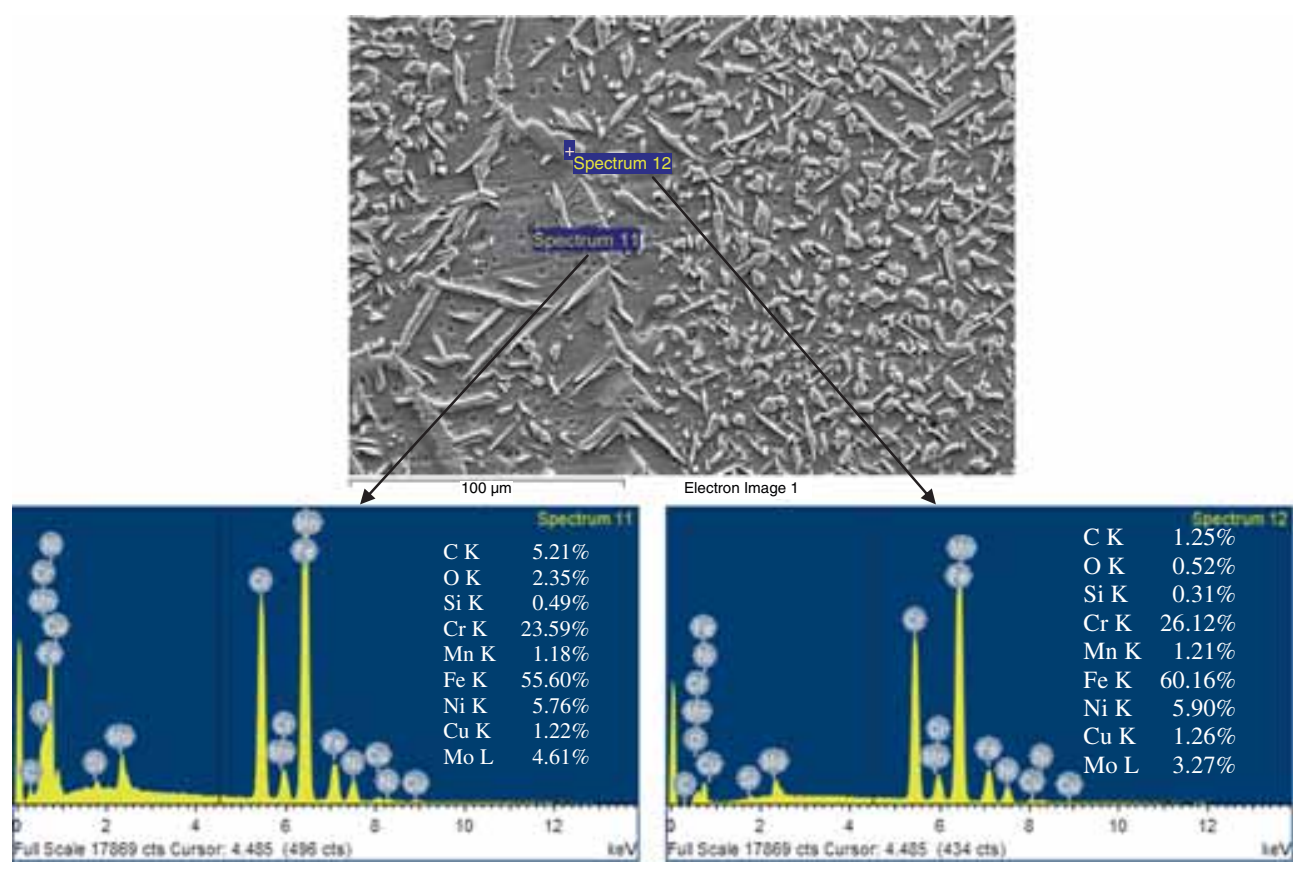

Figure 3. SEM/EDAX point analysis at the weld zone of SDSS weldment employing ER2553 filler.

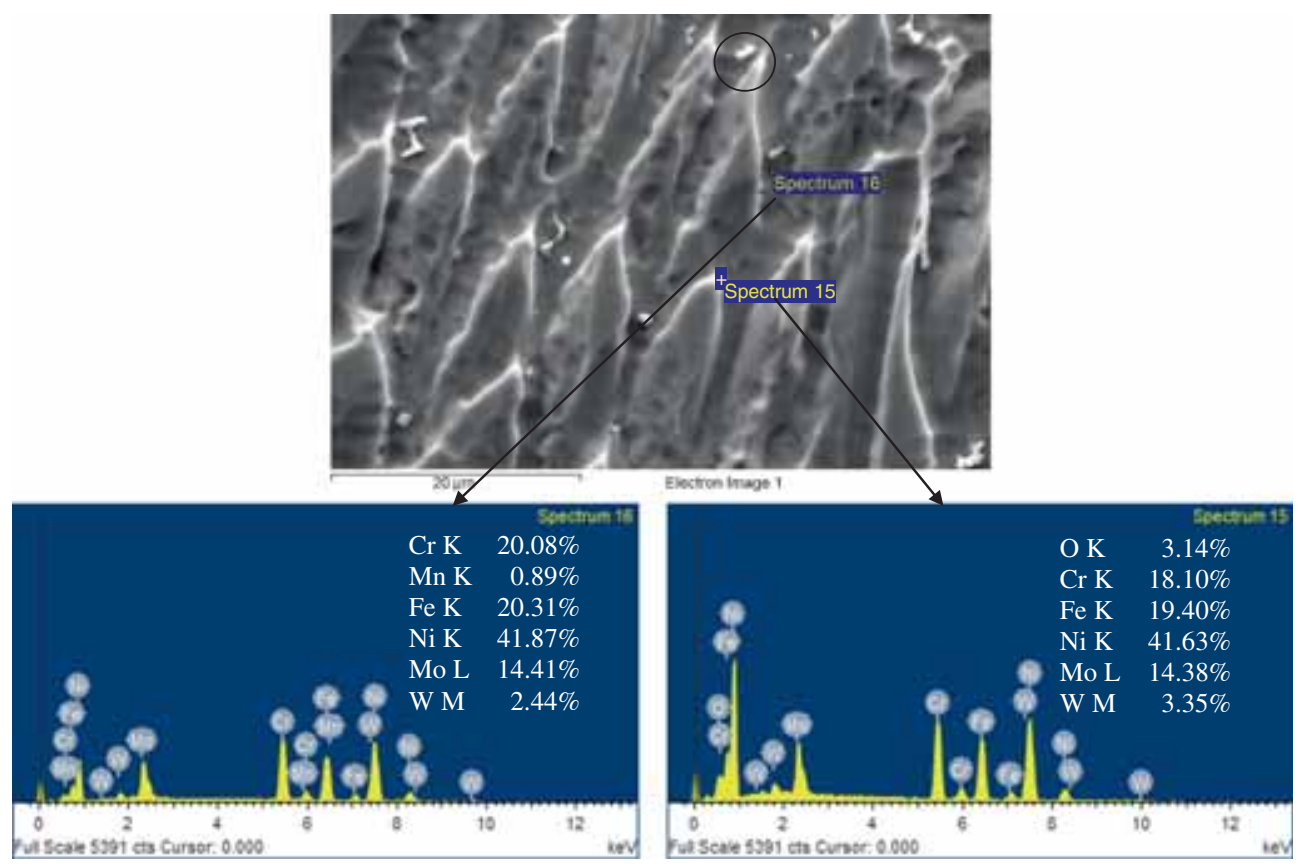

Figure 4. SEM/EDAX point analysis at the weld zone of SDSS weldment employing ERNiCrMo-4 filler.

was $335 \mathrm{HV}$. The maximum hardness was observed at the cap region of the weldment which was found to be $346 \mathrm{HV}$. On the other hand, the hardness values were plummeted at the weld zone employing ERNiCrMo-4 filler. The average weld hardness was observed to be $260 \mathrm{HV}$ whereas the weldment showed an average hardness of $282 \mathrm{HV}$. The cumulative hardness data for both the weldments are shown in table 3 . 3.3b Tensile and impact studies: Tensile results demonstrated that the weldments employing ER2553 filler offered better tensile strength (810 $\mathrm{MPa}$ ) compared with ERNiCrMo-4 (759.5 MPa). Tensile failures occurred at the parent metal (ER2553 weldment) and at the weld zone (ERNiCrMo-4 weldment) shown in figure 6. The cumulative tensile properties of the weldments are represented in table 4. Further SEM fractographs showed the presence 

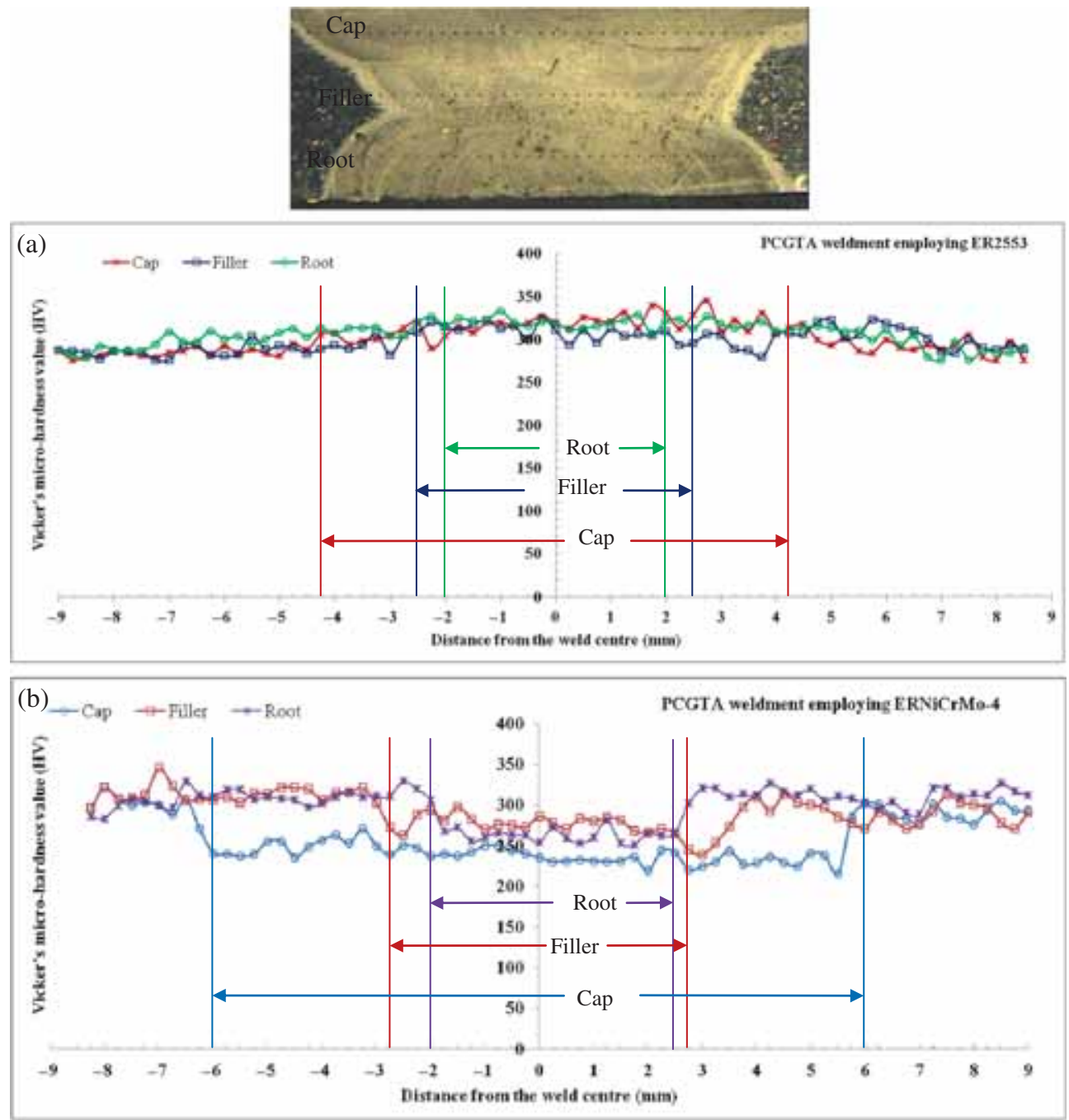

Figure 5. Hardness measurement of PCGTA weldment of SDSS employing (a) ER2553 and (b) ERNiCrMo-4 filler.

Table 3. Cumulative hardness measurements on the PCGTA weldments of super-duplex stainless steel.

\begin{tabular}{|c|c|c|c|c|c|c|c|c|}
\hline \multirow[b]{2}{*}{ Description } & \multicolumn{4}{|c|}{ ER2553 } & \multicolumn{4}{|c|}{ ERNiCrMo-4 } \\
\hline & Cap & Middle & Root & Average & Cap & Middle & Root & Average \\
\hline Average hardness of the weldment (HV) & 302 & 299 & 307 & 303 & 257 & 292 & 298 & 282 \\
\hline Average hardness at the weld zone (HV) & 316 & 309 & 320 & 315 & 241 & 274 & 265 & 260 \\
\hline Peak hardness at the weldment (HV) & 346 & 325 & 333 & 335 & 321 & 345 & 330 & 332 \\
\hline
\end{tabular}

of macro- and micro-voids and ductile tearing ridges network for ER2553 weldments; whereas the fractured matrix showed the presence of minute secondary phases along with macro/micro-voids for ERNiCrMo-4 weldments (figure 7).

Impact studies showed that the weldments employing ER2553 filler experienced better toughness compared with ERNiCrMo-4 weldments. The average impact toughness of ER2553 and ERNiCrMo-4 welds was found to be 144 and $97 \mathrm{~J}$, respectively. Visual examination (figure 8) clearly envisaged that the fracture had not occurred completely except notch deformation in both the cases. SEM fractograph of the impact tested ER2553 weldment depicted the presence of micro-voids and ductile tearing ridges running across the faceted morphology. Similarly cracked boundaries along with the inter-metallics appearing as precipitates were vividly observed on the fractured surface of the weldments employing ERNiCrMo-4 filler (figure 9). Table 5 shows the impact test data of the PCGTA weldments of SDSS. 

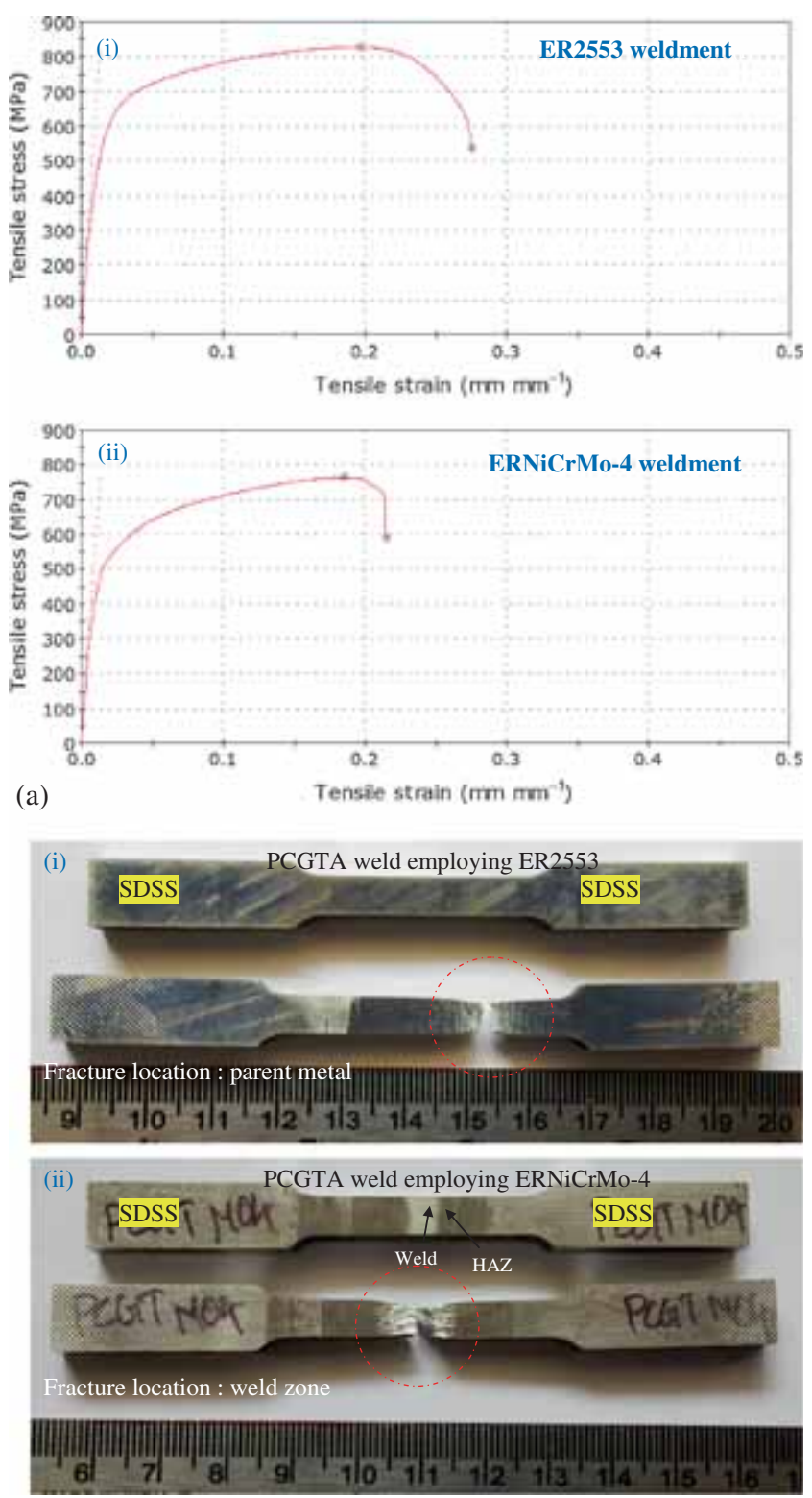

(b)

Figure 6. (a) Stress-strain plots of tensile samples of PCGTA weldments of super-duplex stainless steel and (b) tensile photographs showing the PCGTA weldments employing (i) ER2553 and (ii) ERNiCrMo-4 filler before and after test.

\section{Discussion}

It is well elucidated from the study that the PCGTA welding could be adopted for joining SDSS plates using ER2553 and ERNiCrMo-4 filler wires. Gamma-ray NDT inspection and macrostructure studies clearly portrayed that the weldments are free from any surface defects such as porosity, undercut, lack of penetration and inclusions, etc.

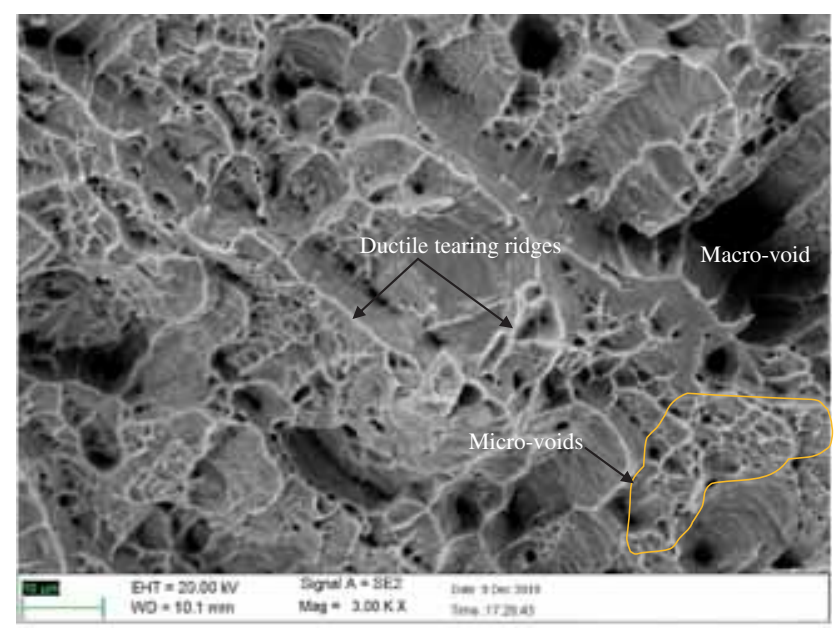

(a)

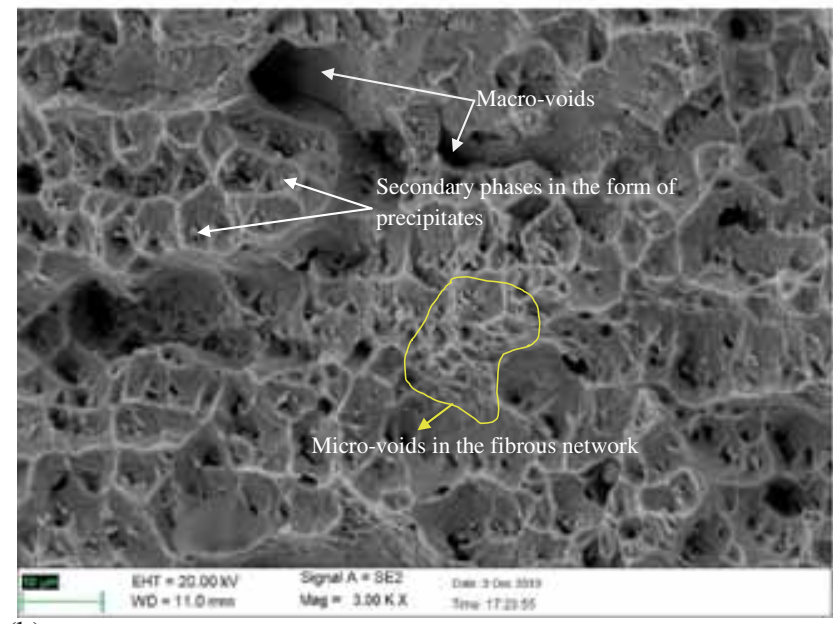

(b)

Figure 7. SEM fractographs showing the fractured surface of the PCGTA weldments employing (a) ER2553 and (b) ERNiCrMo-4 filler.

Table 4. Tensile properties of the PCGTA weldments of super-duplex stainless steel.

\begin{tabular}{|c|c|c|c|c|c|c|}
\hline \multirow[b]{3}{*}{ Property } & \multicolumn{6}{|c|}{ PCGTA welding of super-duplex stainless steels } \\
\hline & \multicolumn{3}{|c|}{ ER2553 } & \multicolumn{3}{|c|}{ ERNiCrMo-4 } \\
\hline & Trial 1 & Trial 2 & Average & Trial 1 & Trial 2 & Average \\
\hline Maximum load (kN) & 27.6 & 27.8 & 27.7 & 27.3 & 27.5 & 27.4 \\
\hline Max. tensile strength (MPa) & 791 & 829 & 810 & 755 & 765 & 760 \\
\hline Tensile strain at break (\%) & 28.94 & 27.53 & 28.2 & 21.78 & 21.51 & 21.6 \\
\hline Elongation at break (\%) & 27.86 & 26.31 & 27.1 & 20.32 & 20.17 & 20.2 \\
\hline Fracture zone & \multicolumn{3}{|c|}{ Parent metal } & \multicolumn{3}{|c|}{ Weld } \\
\hline
\end{tabular}




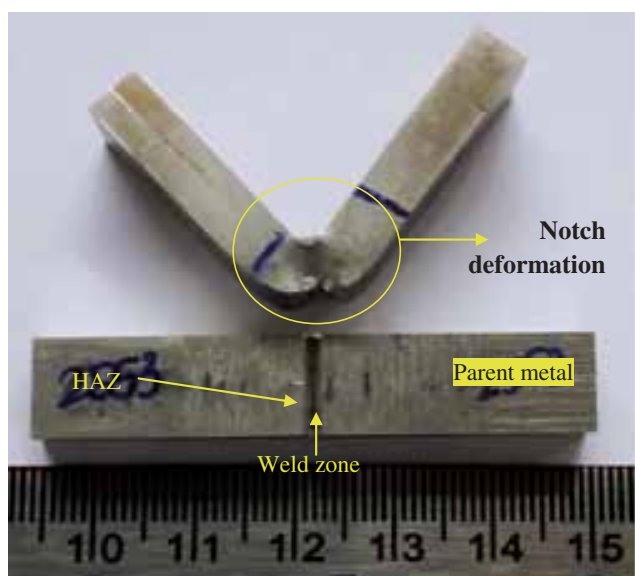

(a)

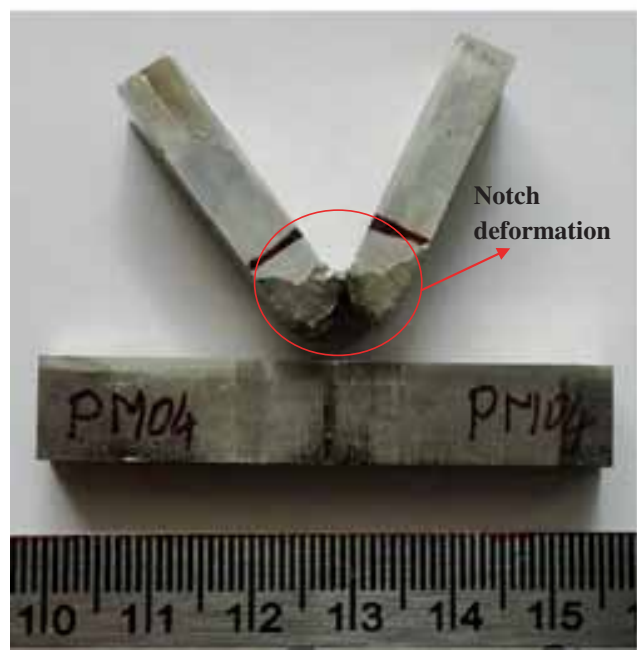

(b)

Figure 8. Impact test samples of PCGTA weldments employing (a) ER2553 and (b) ERNiCrMo-4 fillers, respectively, before and after test.

Microstructure examination of the weld zone employing ER2553 filler divulged the formation of different forms of austenite such as grain boundary austenite, elongated platelets of allotriomorphic and wedge-shaped Widmanstätten austenite and intergranular precipitates originating from ferrite. Similar observations were reported elsewhere. ${ }^{12,13}$ Wang et $a l^{8}$ reported that PCGTA welding coupled with a faster cooling rate could induce the content of austenite to increase under conditions without the addition of alloy or post-weld heat treatment. The solidification mode of the weldments employing ER2553 filler would be ferriticaustenitic (FA) mode. Multi-directional grain growth was observed in the weld zone employing ERNiCrMo-4 filler. The differences in grain growth could be attributed to the varying heat inputs and differences in the cooling rates developed due to the reheating of the fusion zones during multi-pass welding. Also the heat input and the welding speed can affect the solidification mode of the weld metal significantly. ${ }^{14}$ Moreover the SEM analysis (figure $3 b$ ) depicted the presence of inter-metallics at the inter-dendritic

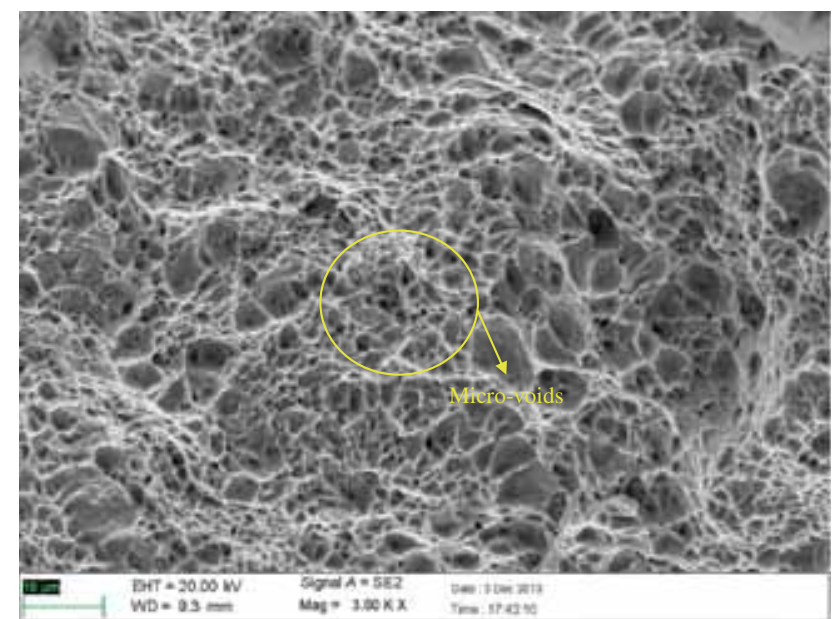

(a)

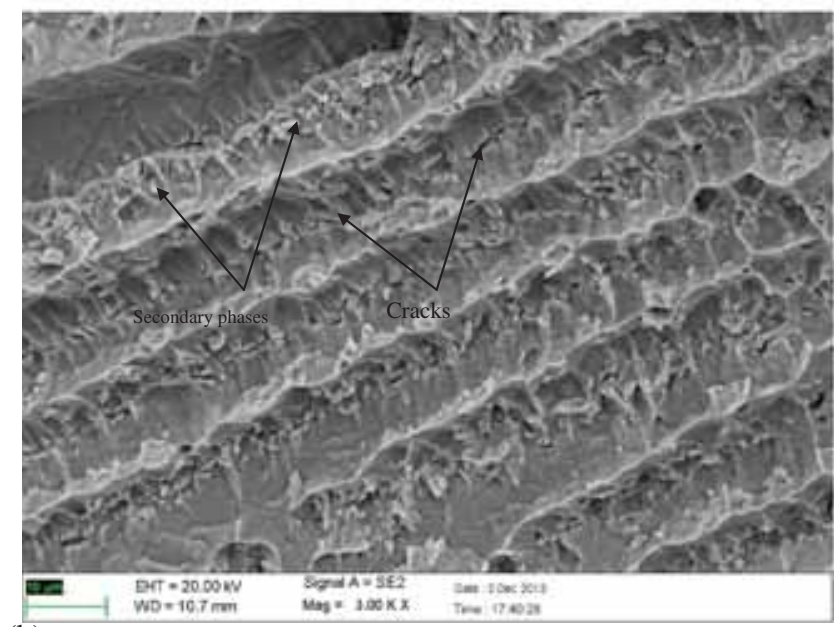

(b)

Figure 9. SEM fractographs of the impact tested SDSS weldment employing (a) ER2553 and (b) ERNiCrMo-4 filler wire, respectively.

arms of the weld zone. These inter-metallic compounds are enriched with $\mathrm{Ni}, \mathrm{Fe}, \mathrm{W}$, Mo and $\mathrm{Cr}$. The welds produced by ERNiCrMo-4 could be austenitic-ferritic in nature which is also witnessed from the SEM/EDAX analysis showing higher amounts of $\mathrm{Ni}$ and $\mathrm{Cr}$. Due to the presence of $\mathrm{Ni}$, an austenite stabilizing element and also ferrite stabilizers such as $\mathrm{Cr}$ and Mo, the solidification shall be austeniteferritic (AF) mode of solidification. As reported by Cao and Hertzman, ${ }^{15}$ the multi-pass welding could cause diffusional transformation of ferrite to austenite in the reheated areas as well as precipitation of inter-metallic phases provided that the cooling rate is slower and temperature of the reheated zone could be approximately $700-800^{\circ} \mathrm{C}$. Since the cooling rate of PCGTA welding is slower compared with EBW, LBW processes and also multi-pass welding is carried out in this study, the inter-metallic phases were found to be prominent while employing ERNiCrMo-4 filler.

Hardness measurements deliberately conveyed that there were no much differences in the hardness values across the 
Table 5. Impact properties of the PCGTA weldments of SDSS at room temperature condition.

\begin{tabular}{lccccc}
\hline & \multicolumn{3}{c}{ PCGTA weldments employing filler } \\
\cline { 2 - 5 } Impact property & Trial 1 & Trial 2 & Average & Trial 1 & Trial 2 \\
\hline $\begin{array}{lccccc}\text { Impact energy (J) } \\
\text { Fracture mode }\end{array}$ & $\begin{array}{c}146 \\
\text { Ductile }\end{array}$ & $\begin{array}{c}142 \\
\text { Brittle }\end{array}$ & 144 & 104 & 90 \\
\hline
\end{tabular}

different zones of the weldments on employing ER2553. This could be attributed to the chemical composition of the filler and the parent metal which is well matched with each other. This is in agreement with the work carried out by Udayakumar et al. ${ }^{16}$ Also as evident from the microstructure studies, the presence of significant amounts of ferrite and different forms of austenite such as inter- and inter-granular precipitates and wedge-shaped Widmänstatten austenitic plates contributed for maintaining the hardness in the weld. It is evident that there were no signs of any inter-metallic phases due to the uniformity in the hardness profile. The hardness got plummeted in the weld zone on employing ERNiCrMo-4 which is reasoned out due to the presence of lesser amount of ferrite as the welds produced by this filler would be completely austenitic or austenitic-ferritic. Because of an appropriate ferrite-austenite ratio, the weld hardness was found maximum on employing ER2553 filler. However, both the filler wires have yielded hardness values which are close to the acceptable, maximum limit imposed by the Norsok standard ( $350 \mathrm{HV})$.

The enhancement in the hardness values at the weld can be attributed to $\mathrm{Cr}_{2} \mathrm{~N}$ and/or $\varepsilon$-phase precipitation. ${ }^{12} \mathrm{How}$ ever, chromium nitride precipitation could not be detected in the present study as per the OM and SEM analysis. Also the nitrogen probably dissolves in the austenite phase due to the slow cooling rate produced by the welding process. Moreover thin foil transmission electron microscopy (TEM) analysis is required to confirm the $\mathrm{Cr}_{2} \mathrm{~N}$ precipitation which is not addressed in the present study.

Tensile results corroborated that the higher tensile strength and ductility were offered by the ER2553 weldments. The tensile fracture occurred at the parent metal for ER2553 weldment and for ERNiCrMo-4 weldment, it was in the weld zone. This is well matching and supporting with the hardness data. It is observed that the weld hardness of ERNiCrMo-4 weldments plummeted due to the presence of completely austenitic or austenitic-ferritic phase. However, the microstructure at the weld zone of ER2553 weldment clearly nurtured the presence of ferrite and austenite in appropriate proportions which contributed for higher hardness and maximum strength of the weldment. Florin $e a^{17}$ reported that the ferrite content in the weld metal should be in the range of 35-65\% to get better strength and toughness. SEM fractograph of ER2553 weldment showed the presence of macro/micro-voids with ductile tearing ridges corroborating that the weldments underwent plastic deformation and absorbed higher amounts of energy before failure occurred. It could be elucidated that the failure in
ER2553 weldments was abruptly of ductile mode; whereas the presence of scarce dimples and bulk voids along with secondary phases contributed for a mixed mode of fracture in case of ERNiCrMo-4 weldments. This could also be well reiterated from the ductility values observed in the study.

It is observed from the charpy V-notch impact test that the ER2553 weldments proffered average impact strength of $144 \mathrm{~J}$ compared with the ERNiCrMo-4 weldments $(97 \mathrm{~J})$. The pinnacled impact resistance of ER2553 weldments could be trait to the presence of higher amounts of ferrite constituent. The weld toughness is also affected by the ferrite content and by oxygen content. As reported by Sindu Kuo, ${ }^{14}$ the duplex weld metal of lower oxygen content, in general, produce weld metal of higher toughness. Also the author reported that GTAW with matching filler metals will exhibit lower as welded toughness due to high ferrite contents and recommended to employ $\mathrm{Ni}$ boosted fillers. But the present study reported the use of matching filler (ER2553) with appropriate weld process parameters yielded better toughness in comparison to the Ni-rich filler ERNiCrMo-4. The toughness of ERNiCrMo-4 was slightly lowered due to the austenitic phase in it and the values observed in the study were higher compared with the earlier works carried out by other researchers. ${ }^{12,16}$ It is inferred clearly that the failure has not occurred completely during impact testing, however plastic deformation took place at the grooved end for both the fillers; still the deformation was very much lower for ER2553 as compared with ERNiCrMo-4 weldments. Further SEM analysis showed the presence of higher amounts of micro-voids spread throughout the ruptured surface for ER2553 weldments which enunciated for typical ductile fracture. On the other hand, the cracked boundaries with the presence of secondary phases appearing as intermetallics clearly represented that these weldments had undergone brittle mode of fracture.

\section{Conclusions}

This study investigated the microstructure and mechanical properties of PCGTA welded SDSS plates employing two different fillers such as ER2553 and ERNiCrMo-4. The nutshell information obtained from the investigation has been summarized as follows:

(a) Successful weld joints of SDSS could be achieved using the current pulsing welding technique employing both the filler wires. 
(b) Weld microstructure of ER2553 weldments showed the presence of ferrite and different forms of austenite such as grain boundary austenite, Widmanstätten austenite and inter/intra-granular austenite.

(c) No significant variations observed in the hardness trend of ER2553 due to the matching composition of filler and base metal. Due to the presence of intermetallic phases, the hardness values plummeted for ERNiCrMo-4 welds.

(d) Tensile failures occurred at the parent metal while employing ER2553 filler whereas the fracture took place in the weld zone for ERNiCrMo-4 filler. It clearly indicated that the weld strength was superior compared with the base metal while employing ER2553 filler.

(e) The impact resistance of ER2553 weldments was found to be higher due to appropriate ferrite-austenite content.

(f) Superior mechanical properties in terms of the weld strength and impact toughness were offered by ER2553 compared with an over-alloyed Ni-based filler wire ERNiCrMo-4. Based on the outcomes, the present study recommends the use of ER2553 for joining SDSS using PCGTA welding process.

\section{References}

1. Gooch T G 1982 Conference on duplex stainless steels' 82 (St. Louis, MO: ASM 573)

2. ASM Specialty handbook on stainless steels 1994 (Ohio: American Society for Metals)
3. Muthupandi V, Bala Srinivasan P, Seshadri S K and Sundaresan S 2003 Mater. Sci. Eng. A 3589

4. Karunakaran N 2012 Int. J. Eng. Technol. 21908

5. Cottis R A and Newman R C 1995 Stress corrosion cracking resistance of duplex stainless steels, Health and Safety Executive-Offshore Technology UK HMSO Report

6. Hsieh R I, Liou H Y and Pan Y T 2001 J. Mater. Sci. Perform. 10526

7. Norsok Standard M601-94 2004 Welding and inspection of piping. Lysaker (Norway: Standards Norway)

8. Wang S-H, Chiu P-K, Yang J-R and Fang J 2006 Mater. Sci. Eng. A 42026

9. Yousefieh M, Shamanian M and Saatchi A 2011 J. Iron Steel Res. Int. 1878

10. Alber Sadek A, Abass M, Zaghloul B, Elrefaey A and Ushio M 2011 Trans. JWRI 2921

11. Gooch T G 1996 Welding Res. Suppl. 135s

12. Tavares S S M, Pardal J M, Lima L D, Bastos I N, Nascimento A M and de Souza J A 2007 Mater. Charact. 58610

13. Devendranath Ramkumar K, Thiruvengatam G, Sudharsan S P, Mishra D, Arivazhagan N and Sridhar R 2014 Mater. Des. 60 125

14. Sindu Kuo 2003 Welding metallurgy (Hoboken, New Jersey: John Wiley \& Sons, Inc.)

15. Cao L and Hertzman S 1991 Proceedings of the duplex stainless steel '91, Vol 1 p 363

16. Udayakumar T, Raja K, Tanksale Abhijit and Sathiya P 2013 J. Manuf. Process. 15558

17. Florin C, Alin N and Dan D 2010 Annals of the Oradea University (Fascicle of Management and Technological Engineering IX) (XIX) 